DUTRNAI, RIS'IT
(Rekayasa Sistem dan Teknologi Informasi)
Vol. 4 No. 5 (2020) $854-863 \quad$ ISSN Media Elektronik: 2580-0760

\title{
Penerapan Firebase Realtime Database pada Aplikasi E-Tilang Smartphone berbasis Mobile Android
}

\author{
Ilham Firman Maulana \\ Teknik Informatika, Fakultas Teknologi Informasi, Universitas Kristen Satya Wacana \\ 672016094@student.uksw.edu
}

\begin{abstract}
Traffic violations are familiar things on the highway. For road users who commit traffic violations will be given sanctions such as reprimands, warnings or given a ticket. The speeding ticket is a medium for the police to write fines and violations against road users who commit traffic violations. In this modern era ideas and ideas have emerged to develop a system or application that can facilitate the performance, needs and human activities through an intermediary smartphone. E-ticketing is a digitization of the manual ticketing process that fills offenders data on the ticketing sheet. The e-ticket helps the police in the ticketing process by entering data in the application, utilizing the Firebase Realtime Database technology through smartphone intermediaries. The purpose of this study is to create a traffic violator or E-ticketing system using the Firebase Realtime Database technology. Then provide attachments to offenders in the form of notifications through the E-ticket application, and assist the police in an effort to deal with traffic offenders. The results of this study showed $80.5 \%$ of respondents rated the Application of Firebase Realtime Database on the Android-based Smartphone Mobile ETicket Application in accordance with the needs of the police in carrying out the ticketing process.
\end{abstract}

Keywords: E-Tilang, Firebase, Realtime, Smartphone, Android

\begin{abstract}
Abstrak
Pelanggaran lalu lintas merupakan hal yang tidak asing kita lihat di jalan raya. Bagi pengguna jalan raya yang melakukan pelanggaran lalu lintas akan diberikan sanksi seperti teguran, peringatan atau diberi surat tilang. Surat tilang merupakan media bagi pihak kepolisian untuk menuliskan denda dan pelanggaran terhadap pengguna jalan raya yang melakukan pelanggaran lalu lintas. Di era modern ini bermunculan ide dan gagasan untuk mengembangkan suatu sistem atau aplikasi yang dapat mempermudah kinerja, kebutuhan serta aktifitas manusia melalui perantara smartphone. E-tilang merupakan digitalisasi dari proses penilangan manual yang mengisi data pelanggar pada lembar surat tilang. E-tilang membantu pihak kepolisian dalam proses penilangan dengan memasukan data di dalam aplikasi, memanfaatkan teknologi Firebase Realtime Database melalui perantara smartphone. Tujuan penelitian ini membuat sistem tindak pelanggar lalu lintas atau E-tilang dengan menggunakan teknologi Firebase Realtime Database. Kemudian memberikan attachment ke pelanggar berupa notifikasi melalui aplikasi E-tilang, dan membantu pihak kepolisian dalam upaya menangani tindak pelanggar lalu lintas. Hasil dari penelitian ini menunjukkan 80,5\% dari responden, menilai Penerapan Firebase Realtime Database pada Aplikasi E-Tilang Smartphone berbasis Mobile Android sesuai dengan kebutuhan pihak kepolisian dalam melaksanakan proses tilang.
\end{abstract}

Kata kunci: E-Tilang, Firebase, Realtime, Smartphone, Android

\section{Pendahuluan}

atau diberi surat tilang. Surat tilang merupakan media bagi polisi untuk menuliskan denda dan pelanggaran Pelanggaran lalu lintas di Indonesia sering terjadi[1]. terhadap pengguna jalan raya yang melakukan Bagi pengguna jalan raya yang melakukan pelanggaran pelanggaran lalu lintas. Saat ini pihak kepolisian lalu lalu lintas maka akan diberikan sanksi seperti teguran lintas masih menggunakan sistem pencatatan surat tilang

Diterima Redaksi : 30-07-2020 | Selesai Revisi : 04-09-2020 | Diterbitkan Online : 30-10-2020 
secara manual, pencatatan secara manual sendiri yaitu yang akan mendigitalisasi form bukti pelanggaran dengan mengisi data-data pada lembar surat tilang[2].

kemudian akan tersimpan ke dalam database yang

Dengan penerapan sistem E-Tilang masyarakat tidak perlu lagi datang ke pengadilan dengan jadwal yang telah ditentukan, masyarakat hanya perlu datang ke nantinya akan dieksekusi atau disubmit oleh sisi kejaksaan. Server sebagai pihak kejaksaan medianya website.[6]

ATM (Anjungan Tunai Mandiri) atau ke Bank Penelitian yang berjudul "Aplikasi Surat Tilang selanjutnya melakukan transfer ke nomor yang sudah Berbasis Android Menggunakan Teknologi Near Field diberikan oleh petugas yang menilang[3]. Oleh karena Communication (NFC)" yang dilakukan oleh Ridar itu pelanggar lalu lintas tidak perlu datang ke Rusdi, Ardianto Wibowo, Yohana Dewi Lulu W pada persidangan untuk mengambil STNK (Surat Tanda tahun 2013 membahas tentang memanfaatkan Nomer Kendaraan) dan membayar denda sesuai jadwal penggunaan teknologi NFC dan kartu Radio-frequency yang ditentukan, akan tetapi pelanggar hanya cukup identification (RFID) untuk membuat sebuah aplikasi lihat, bayar, dan ambil dalam waktu singkat. Kebijakan surat tilang berbasis Android. Surat tilang ditulis melalui ini berawal dari permasalahan yang terjadi dalam perangkat Android, kemudian data surat tilang disimpan penegakan hukum mengenai pelanggaran-pelanggaran kedalam kartu RFID pelanggar. Selanjutnya pelanggar yang terjadi dalam berlalu lintas mulai dari pungutan akan memberikan kartu RFID kepada hakim saat liar, istilah damai di tempat, masalah sidang tilang di persidangan. Hakim dengan menggunakan perangkat pengadilan hingga akuntabilitas uang denda. Tujuan dari Android nya dapat membaca data surat tilang yang program E-Tilang dianggap mampu menjawab terdapat di dalam kartu RFID pelanggar.[3] permasalahan tersebut dan disambut baik oleh implementor maupun masyarakat[4].

Berdasarkan latar belakang di atas, maka peneliti merancang sebuah aplikasi E-Tilang dengan Penelitian yang berjudul "Aplikasi E-TILANG menggunakan teknologi firebase realtime database. Kendaraan Bermotor Berbasis Android" yang Realtime Database adalah database asli Firebase. Solusi dilakukan oleh Q. A. Subavhe Sandy, Hardhienata ini berlatensi rendah dan efisien untuk aplikasi seluler Soewarto pada tahun 2016 membahas mengenai yang membutuhkan status sinkronisasi di seluruh pembuatan Aplikasi E-Tilang yang digunakan oleh pengguna secara real-time. Tujuan dan manfaat pihak kepolisan dalam tugasnya dalam penilangan. penelitian ini adalah membuat sistem tindak pelanggar Menggantikan media kertas ke media handphone lalu lintas atau E-tilang dengan menggunakan teknologi berbasis Android. Data tilang ini sangat akurat karena Firebase Realtime Database. Kemudian memberikan selain data tilang disertai juga foto pengendara dengan attachment ke pelanggar berupa notifikasi melalui kendaraanya. Pelanggar yang telah ditindak oleh pihak aplikasi E-tilang dan membantu pihak kepolisian dalam kepolisian dapat melihat kebenaran data tilang dan data upaya menangani tindak pelanggar lalu lintas. sidang melalui web yang sudah diberitahukan Perancangan aplikasi E-Tilang ini juga membantu pihak sebelumnya oleh pihak kepolisian saat ditindak di jalan client atau kepolisian dalam proses penilangan dengan raya. [1]

Penelitian yang berjudul "Penerapan Firebase Realtime Database Pada Prototype Aplikasi Pemesanan Makanan Berbasis Android" yang dilakukan oleh G. R. Payara and R. Tanone pada tahun 2018 membahas tentang implementasi pemesanan makan dalam bentuk aplikasi berbasis android yang sangat membantu para Metodologi penelitian merupakan proses untuk konsumen atau pembeli untuk melakukan pemesanan mendapatkan data yang akan digunakan untuk keperluan makanan. Aplikasi ini mempermudah pihak admin dalam melakukan penelitian. Secara detail ilustrasi untuk mengelola data pemesanan. Dalam perancangan penelitian digambarkan pada Gambar 1 .

aplikasi ini menggunakan teknologi Realtime database. Aplikasi ini dapat membantu masyarakat dalam proses memesan makanan menjadi lebih mudah dan efisien.[5] memasukan data di dalam aplikasi. Mengganti proses manualnya mengisi data-data pelanggar pada lembar surat tilang. Aplikasi ini dibuat untuk membantu pihak KorpLantasRI[6]

\section{Metodologi Penelitian}

Gambar 1 menjelaskan tentang metode yang digunakan dalam penelitian ini berguna sebagai proses dalam merancang sistem. Dimana di metodelogi penelitian ini Penelitian yang berjudul "Aplikasi E-Tilang Pada Tablet memiliki 7 fase yaitu identifikasi masalah, studi Sistem Operasi Berbasis Android" yang dilakukan oleh literatur, pengumpulan data, analisa dan perancangan Ibnu Peristiawan Azis pada tahun 2012 membahas sistem, implementasi sistem, pengujian sistem dan tentang merancang sistem dan pembuatan aplikasi E- penyusunan laporan tugas akhir. Berikut penjelasan Tilang yang bertujuan untuk memudahkan tugas dari bagan dari metodologi penelitian.

kepolisian. Perancangan sistem ini terdiri dari perancangan server dan client. Client yang dimaksud 2.1. Identifikasi Masalah

dalam perancangan ini adalah pihak kepolisian. Sistem Di dalam tahap ini peneliti mengidentifikasi masalah ini akan berjalan pada tablet bersistem operasi Android yaitu pihak kepolisian masih menggunakan tilang 
manual yang menyebabkan proses pengambilan STNK Firebase Realtime Database merupakan database yang cukup lama, serta terdapat permasalahan istilah realtime yang tersimpan di cloud dan support damai di tempat ataupun pungutan liat. Tujuan dari multiplatform seperti Android, iOS dan Web. Data pada sistem E-tilang dianggap mampu menjawab firebase akan disimpan dalam struktur JSON (Java permasalahan tersebut dan disambut baik oleh Script Object Notation). Database firebase akan implementor maupun masyarakat[4].

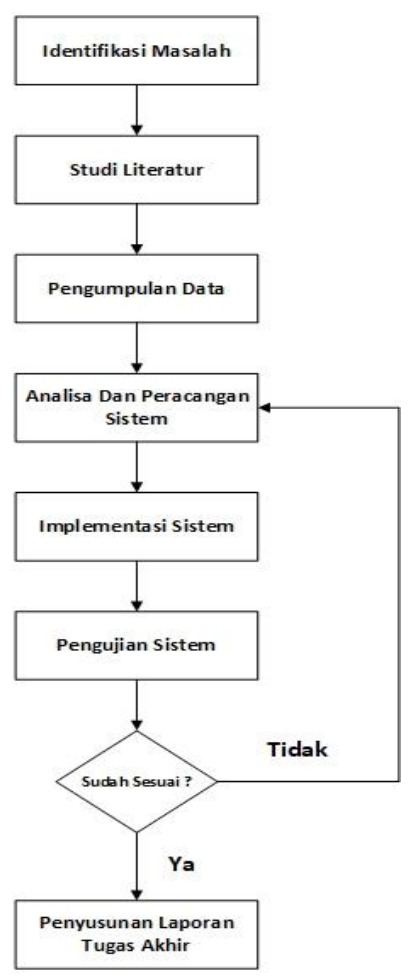

Gambar 1. Bagan Metodologi Penelitian

\subsection{Studi Literatur}

Mekanisme Tilang ini terjadi pada saat pelanggar lalu lintas terbukti melakukan pelanggaran. Dari kepolisian akan melakukan beberapa tindakan, salah satu tindakannya adalah melakukan penilangan dengan cara menuliskan pelanggaran pada formulir warna merah yang berisi identitas pelanggar, jenis pelanggaran, dll. Setelah melakukan penindakan kepolisian menetapkan hari sidang dan menghimbau untuk pelanggar agar menghadiri sidang. Untuk tanggal dan dimana pelanggar harus menghadiri sidang sudah di cantumkan di formulir. Bila pelanggar tidak hadir, kepolisian wajib 2 kali memanggil dan ke 3 kalinya melakukan penangkapan. Pengembalian barang bukti menunggu selesainya sidang dan setelah pelanggar membayar denda ke Panitera.[6]

E-tilang adalah digitalisasi proses tilang, dengan memanfaatkan teknologi, seluruh proses tilang akan lebih efisien dan efektif juga membantu pihak kepolisian dalam manajemen administrasi.[7] Dengan menggunakan aplikasi E-tilang maka dapat menggantikan proses penilangan manual ke proses digitalisasi. Pelanggar lalu lintas akan mendapatkan notifikasi SMS penilangan sesuai format penilangan manualnya. melakukan sinkronisasi secara otomatis terhadap aplikasi client yang terhubung kepadanya. Aplikasi multiplatform yang menggunakan SDK Android, iOS dan JavaScript akan menerima update data terbaru secara otomatis pada saat aplikasi terhubung ke server firebase.[8]

Firebase Realtime Database merupakan platform Database yang digunakan pada aplikasi realtime. Ketika terjadi perubahan data, maka aplikasi yang terhubung dengan firebase akan memperbaharui secara otomatis melalui setiap device (perangkat) baik website ataupun mobile. Firebase mempunyai library (pustaka) yang lengkap untuk sebagian besar platform web dan mobile. Firebase dapat digabungkan dengan framework lain seperti node, java, javascript, dan lain-lain.[9] Terdapat beberapa fitur yang disediakan oleh firebase adalah sebagai berikut :

1. Analytics, fitur ini digunakan untuk mengamati tingkah laku pengguna dalam penggunaan aplikasi dan ditampilkan dalam satu dashboard.

2. Develop, fitur ini berupa cloud messaging, authentication, realtime database, storage, hosting, testlab dan crash reporting.

3. Grow, fitur ini digunakan untuk mempublikasikan sebuah produk aplikasi. Berikut adalah beberapa fitur firebase. Perhatikan Gambar 2.

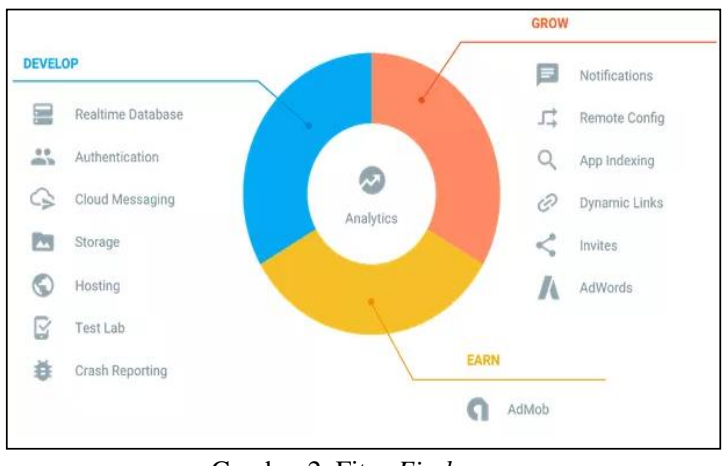

Cloud Firestore merupakan database terbaru dari Firebase untuk pengembangan aplikasi seluler. Database ini melanjutkan keberhasilan Realtime Database dengan model data baru yang lebih intuitif. Cloud Firestore juga memiliki fitur kueri yang lebih lengkap dan lebih cepat, serta penskalaan yang lebih mendalam dibandingkan dengan Realtime Database. Seperti Firebase Realtime Database, Cloud Firestore membuat data tetap terhubung di aplikasi klien melalui listener realtime dan menawarkan dukungan secara offline untuk seluler dan web. Cloud Firestore ini digunakan untuk menampung data kepolisian yang telah melakukan proses registerasi melalui aplikasi Etilang. 


\subsection{Pengumpulan data}

Data yang didapat secara tidak langsung dari objek penelitian (Data sekunder). Data yang diperoleh Dari sisi client adalah nama pelanggar, jenis kelamin, SIM, nomer kendaraan, nomer STNK, denda tilang, nomer hp, keterangan.

\subsection{Analisa \& Perancangan Sistem}

Pada proses perancangan sistem menggunakan bahasa pemodelan UML (Unified Modeling Language) yaitu usecase diagram, activity diagram, pembuatan prototype, perancangan server (website) dan client (aplikasi).

\subsubsection{Usecase}

Usecase diagram merupakan penjelasan keseluruhan kerja dari sebuah sistem secara garis besar.

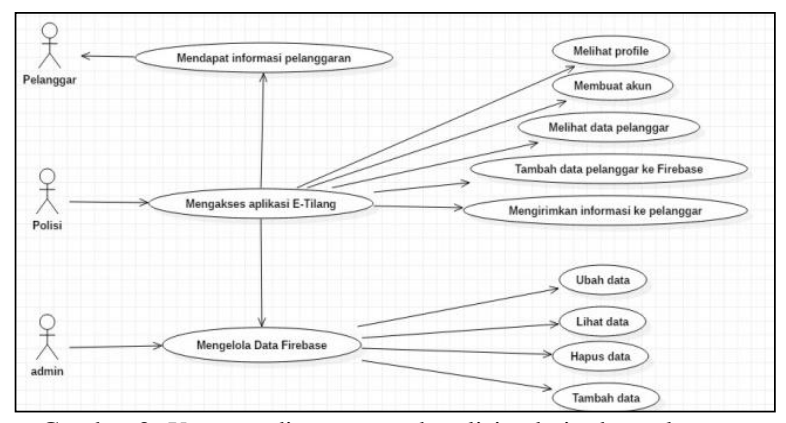

Gambar 3. Use case diagram untuk polisi, admin dan pelanggar

Gambar 3 menunjukan bahwa terdapat 2 pengguna sistem, yang pertama adalah admin yang dapat mengelola data firebase. Kemudian yang kedua adalah polisi yang bisa mengakses aplikasi E-tilang. Disini pelanggar tidak mengakses sistem, akan tetapi mendapatkan notifikasi dari sistem berupa SMS.

Gambar 4 menggambarkan activity diagram yang dapat dilakukan oleh seorang admin. Pertama admin harus menginputkan username dan password firebase, jika berhasil login maka admin bisa mengelola data realtime database E-tilang.

Gambar 5 menggambarkan activity diagram yang dapat dilakukan oleh seorang polisi. Polisi dapat mengakses aplikasi E-tilang, jika polisi belum mempunyai akun maka polisi wajib mendaftarkan akun agar nantinya bisa masuk kehalaman home sistem. Setelah membuat akun maka polisi mendapatkan notifikasi dari firebase untuk verifikasi email. Setelah verifikasi email berhasil polisi memasukan email dan password. Kemudian polisi dapat Gambar 6 dapat dijelaskan, polisi melakukan login dan masuk kedalam sistem aplikasi E-tilang, setelah itu sistem akan melalukan pengecekan ID dan kata kunci. polisi dapat memasukan data pelanggar, melihat profil, ID dan kata kunci sudah dimasukkan atau disimpan di melihat prosedur E-tilang, mengunggah gambar dalam database melalui registrasi akun. Jika ID atau pelanggar, yang terakhir polisi mengirimkan notifikasi kata kunci salah maka polisi akan diminta untuk ke pelanggar.

\subsubsection{Activity Diagram Admin}

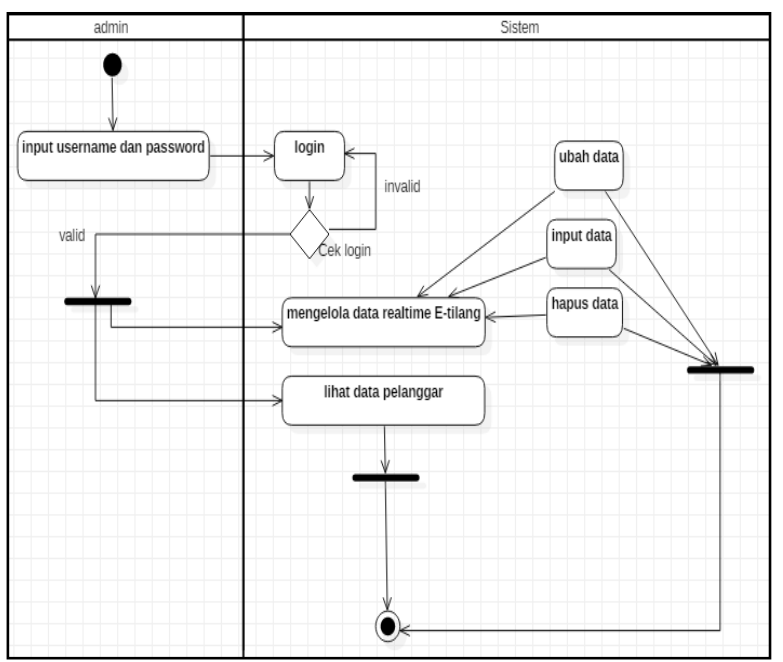

Gambar 4. Activity Diagram Admin

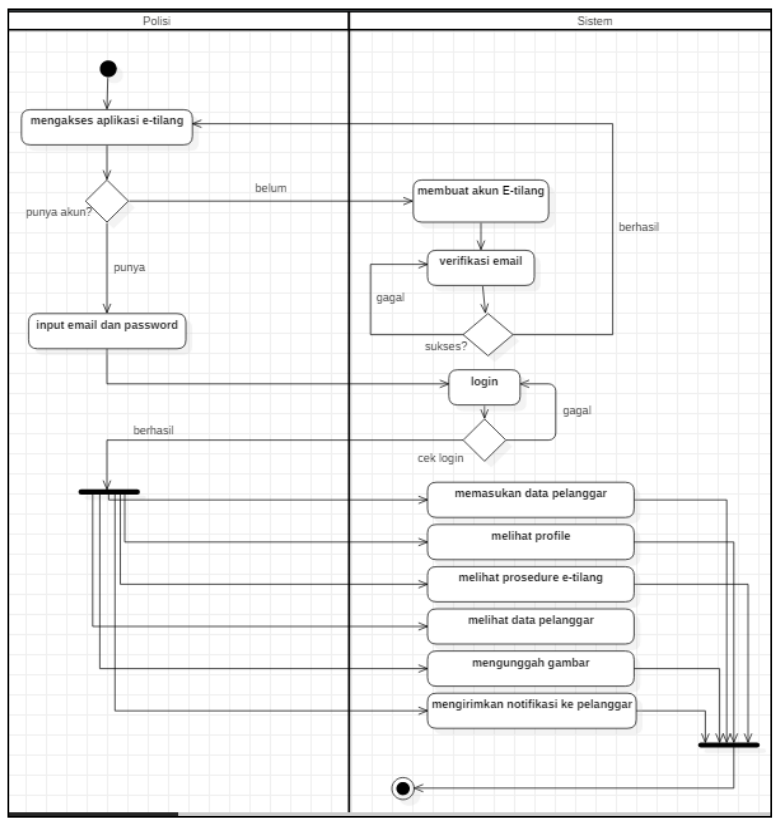

Gambar 5. Activity Diagram polisi

\subsubsection{Sequence Diagram}

Sequance diagram mendeskipsikan alur yang dilakukan sebagai respon dari sebuah input untuk menghasilkan suatu output tertentu. Pada gambar 6 menggambarkan sequence diagram untuk polisi.

memasukkan ID dan kata kunci yang benar dan bila ID dan kata kunci benar maka polisi dapat login untuk melanjutkan ke halaman utama. Saat di halaman utama polisi akan masuk ke halaman E-tilang memasukan data 
pelanggar. Selanjutnya data tersebut akan masuk ke firebase database. Setelah data masuk, maka akan menampilkan hasil berupa notifikasi bahwa data sudah berhasil masuk ke firebase database. Di waktu yang bersamaan, pelanggar akan mendapatkan notifikasi pelanggaranlalu lintas.

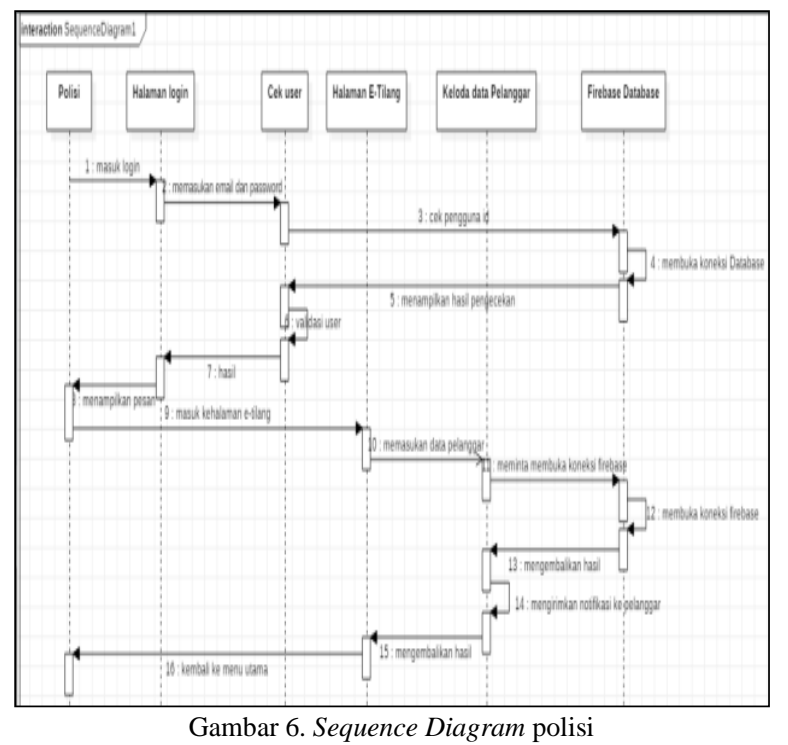

\subsubsection{Arsitektur sistem}

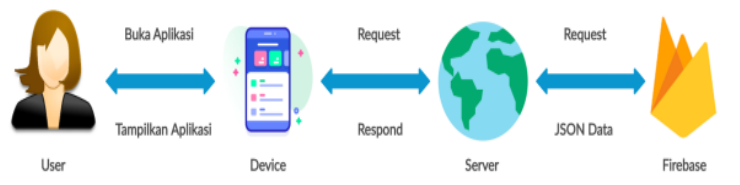

Gambar 7. Perancangan arsitektur sistem

Gambar 7 menjelaskan tentang perancangan arsitektur sistem. Arsitektur sistem ini membahas mengenai pertukaran data dari user, device, server serta firebase yang akan digunakan untuk menampilkan data sesuai permintaan user yang disimpan pada firebase database.

\subsubsection{Rancangan Database Sistem}

Gambar 8 menjelaskan tentang perancangan database sistem secara realtime. Terdapat 2 tabel yaitu tabel ETILANG dan tabel Tilang. Tabel E-TILANG merupakan tabel yang digunakan untuk menampung data gambar. Tabel E-TILANG berisi imageUrl dan nama gambar, data bertambah ketika pengguna menggunakan pilihan upload gambar di aplikasi. Tabel Tilang merupakan tabel yang digunakan untuk menampung data pelanggar, dengan primary key Pelanggar Id, serta data yang muncul merupakan inputan dari user.

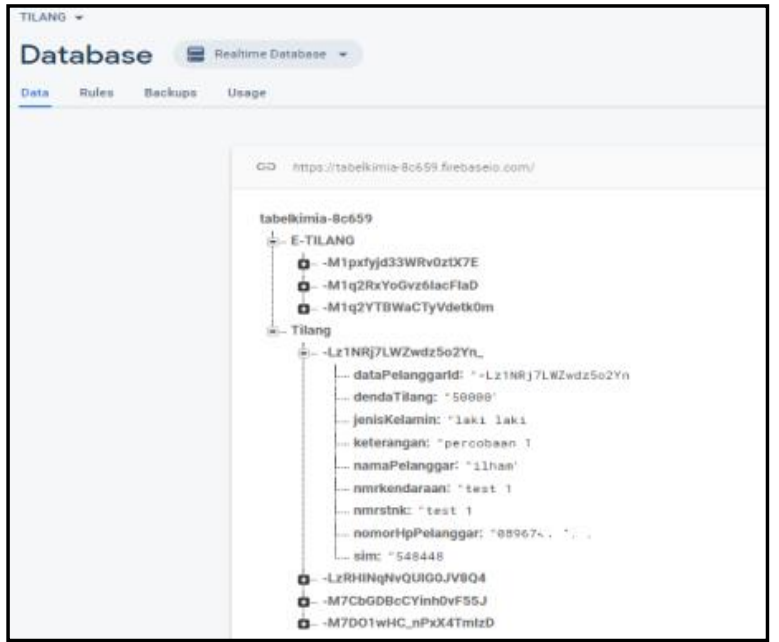

Gambar 8. Rancangan realtime database

\subsubsection{Rancangan Cloud firestore sistem}

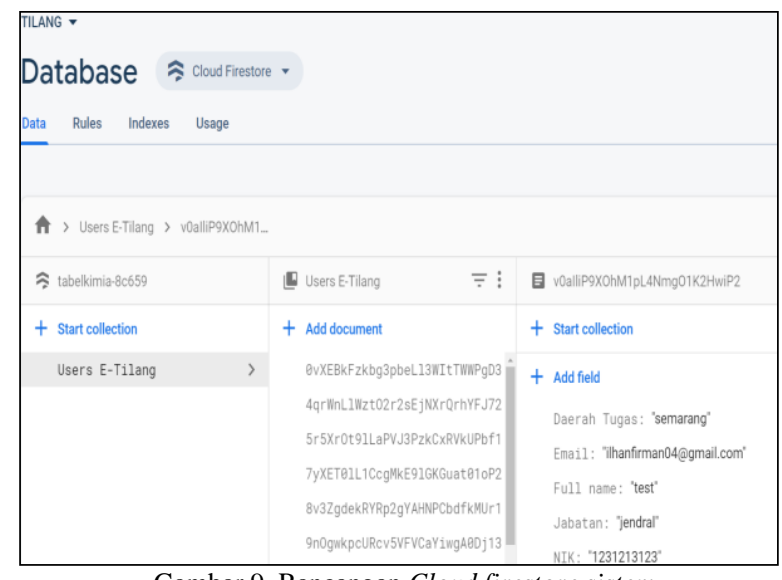

Gambar 9. Rancangan Cloud firestore sistem

Gambar 9 menjelaskan mengenai rancangan database sistem secara Cloud firestore. Data di atas merupakan inputan user ketika melakukan pendaftaran atau registrasi. Setiap data memliki idnya masing - masing, berguna untuk masuk ke menu aplikasi E-tilang. Serta id tersebut berguna sebagai acuan untuk menampilkan keseluruhan data user(polisi) di menu profil E-tilang.

\subsection{Teknik Pengujian Sistem}

User Acceptance Testing merupakan pengujian yang dilakukan oleh end-user dimana user tersebut adalah staff/karyawan perusahaan yang langsung berinteraksi dengan sistem dan dilakukan verifikasi apakah fungsi yang ada telah berjalan sesuai dengan kebutuhan/fungsinya.[10] Setelah dilakukan system testing, acceptance testing menyatakan bahwa sistem software memenuhi persyaratan. Acceptance testing merupakan pengujian yang dilakukan oleh pengguna yang menggunakan teknik pengujian black box untuk menguji sistem terhadap spesifikasinya. Pengguna akhir bertanggung jawab untuk memastikan semua fungsionalitas yang relevan telah diuji. [11] 


\section{Hasil dan Pembahasan}

Hasil penelitian yang dilakukan berupa penerapan firebase realtime database pada aplikasi E-Tilang smartphone berbasis mobile android. Sistem ini dapat mempermudah pihak kepolisian dalam menindak pelanggar lalu lintas. Serta membantu pelanggar lalu lintas dalam pengembilan STNK. Sistem ini menggunakan firebase realtime database sehingga data yang diperoleh adalah realtime. Firebase Realtime Database merupakan database yang tersimpan di cloud dan support multiplatform seperti Android, iOS dan Web. Database firebase akan melakukan sinkronisasi secara otomatis terhadap aplikasi client yang terhubung kepadanya.

\subsection{Implementasi Sistem}

Tahap implementasi ini mewujudkan konsep perancangan sistem menjadi aplikasi yang akan siap untuk digunakan dan menerepakan Firebase Realtime Database. Pada sisi client user yang menggunakannya adalah dari pihak kepolisian.

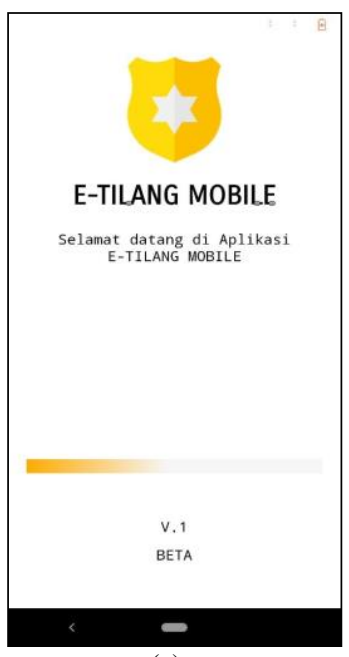

(a)

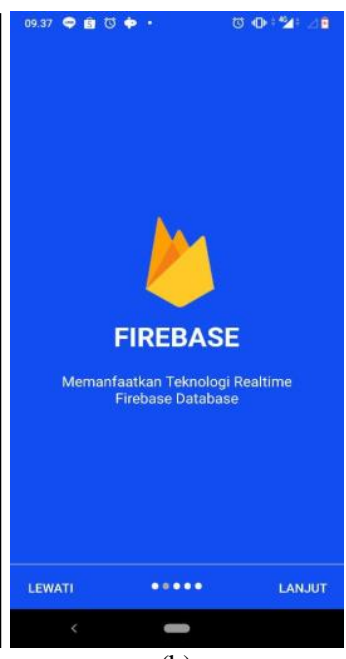

(b)
Gambar 10. (a) Aplikasi dijalankan (b) Halaman pertama

Gambar 10(a) dan 10(b) merupakan tampilan awal ketika aplikasi pertama kali dijalankan.

Gambar 11(a) merupakan tampilan halaman login dan halaman register. Jika user sudah memiliki akun maka bisa masuk dan menuju ke halaman menu aplikasi. Namun jika user belum memiliki akun maka wajib untuk melakukan register atau create account. Gambar 11(b) merupakan tampilan register, pihak kepolisan wajib register agar bisa login. Sistem register ini menggunakan fungsi Autentifikasi Firebase Database. Jadi email, password dan data diri akan masuk ke dalam database firebase. Ketika menekan daftar maka user akan mendapatkan email verifikasi dari Firebase.

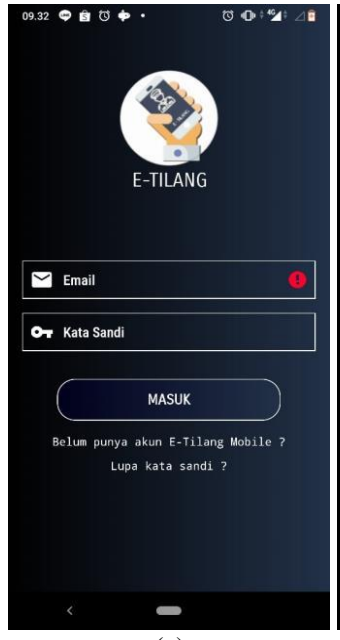

(a)

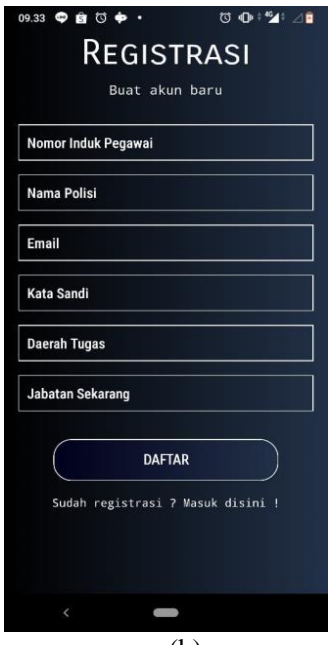

(b)
Gambar 11. (a) Halaman Login (b) Halaman Register.

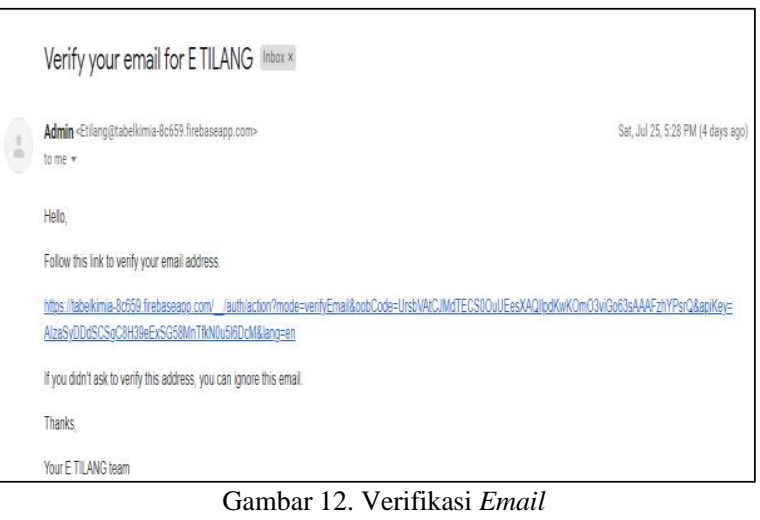

Gambar 12 merupakan tampilan email verifikasi untuk user. Setelah diverifikasi maka user bisa masuk ke dalam aplikasi E-tilang.

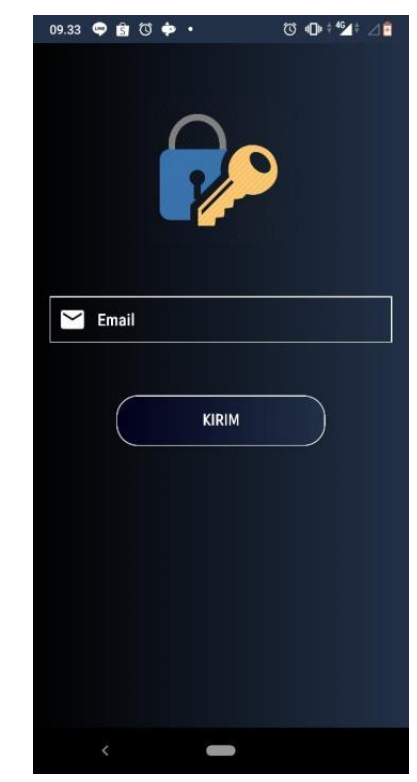

Gambar 13. Tampilan lupa kata sandi 
Gambar 13 merupakan tampikan lupa kata sandi memanfaatkan fitur pada firebase. User memasukan email maka akan mendapatkan notifikasi email untuk mengubah kata sandi.

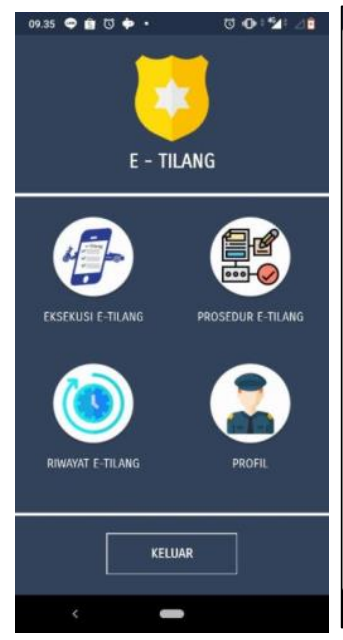

(a)

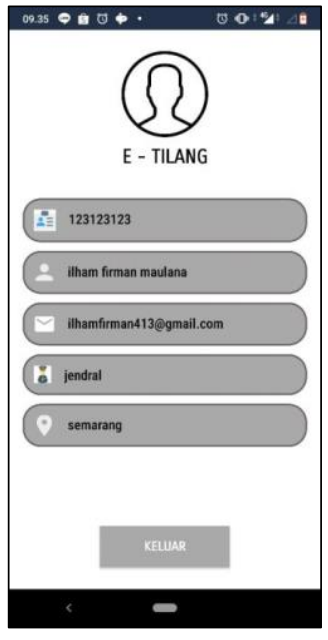

(b)
Gambar 14. (a) Halaman Menu (b) Profile

Gambar 14 (a) merupakan tampilan menu dari aplikasi E-tilang terdapat 4 pilihan didalamnnya yaitu eksekusi tilang, prosedur tilang, riwayat tilang dan profil. Gambar 14 (b) merupakan tampilan profil, mengambil dari data firestore firebase.

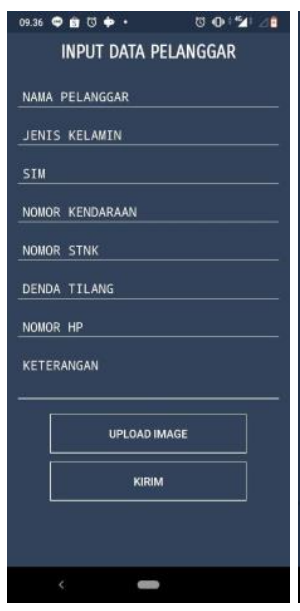

(a)

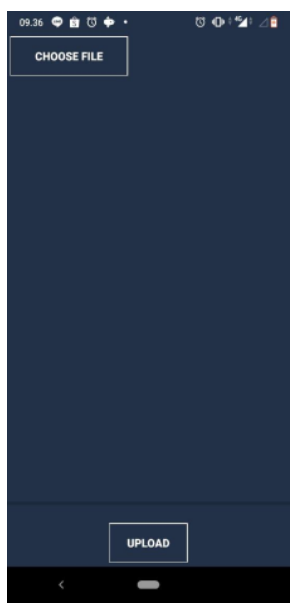

(b)
Gambar 15. (a) Eksekusi Tilang (b) Upload Image.

Gambar 15 (a) merupakan tampilan eksekusi tilang, ketika pihak kepolisian selesai menambahkan data. Pihak kepolisian wajib menekan tombol kirim, tombol kirim berfungsi untuk memberikan notifikasi $s m s$ ke pelanggar. Gambar 15 (b) merupakan tampilan upload image memanfaatkan fungsi storage firebase. Dari pihak kepolisan bisa upload image dan masuk ke dalam database firebase.

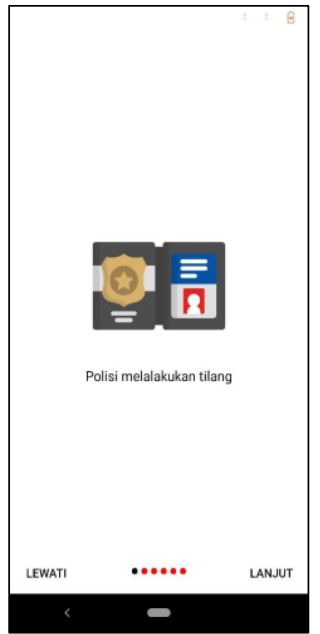

(a)

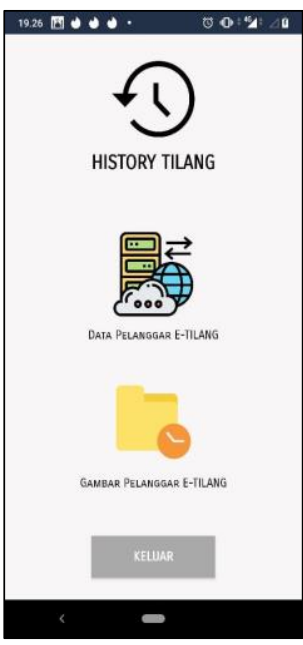

(b)
Gambar 16. (a) Prosedur E -tilang (b) History Tilang.

Gambar 16(a) merupakan tampilan prosedur E-tilang. Yang berfungsi sebagai penjelasan kepada masyarakat yang awam mengenai alur proses E-tilang. Prosedur ini akan dijelaskan oleh pihak kepolisian secara face to face. Gambar 16(b) merupakan tampilan history tilang, yang berisi gambar pelanggar tilang dan data pelanggar tilang.

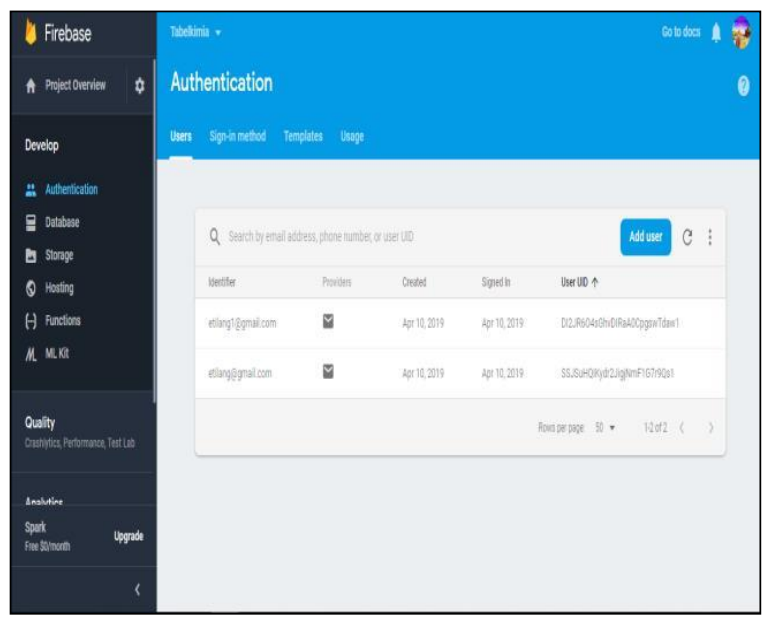

Gambar 17. Autentifikasi Firebase Database

Gambar 17 menjelaskan mengenai ketika user sudah melakukan registrasi maka email dan password akan masuk kedalam firebase database.

Gambar 18 menjelaskan jika program aplikasi E-tilang dijalankan, setelah polisi menginputkan data dan menekan tombol kirim maka aplikasi ini akan mengirimkan SMS ke nomer pelanggar melalui fitur SMS manager. SMS tersebut berisi data-data yang telah diinputkan oleh kepolisian. Dari implementasi diatas masih perlu perbaikan berupa user interface , penambahan fitur dan penambahan function program agar menjadi lebih baik. 


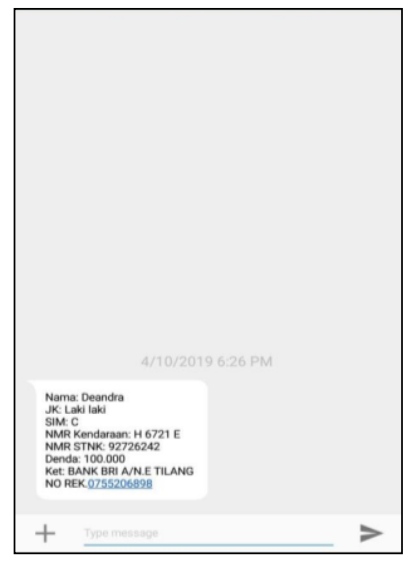

Gambar 18. Tampilan SMS E-Tilang

\subsection{Pembahasan dan pengujian performa Firebase}

Pemantauan performa firebase dapat dilakukan dengan berbagai cara. Salah satu cara yang dapat digunakan adalah dengan menggunakan fitur firebase console. Firebase Console merupakan tab penggunaan yang dapat menampilkan informasi tentang koneksi simultan ke database. Firebase Console dapat menampilkan jumlah data yang tersimpan, bandwidth keluar (termasuk overhead protokol dan enkripsi), serta muatan database dalam interval satu menit. Tab penggunaan memberikan ringkasan performa database secara keseluruhan dengan lebih akurat.

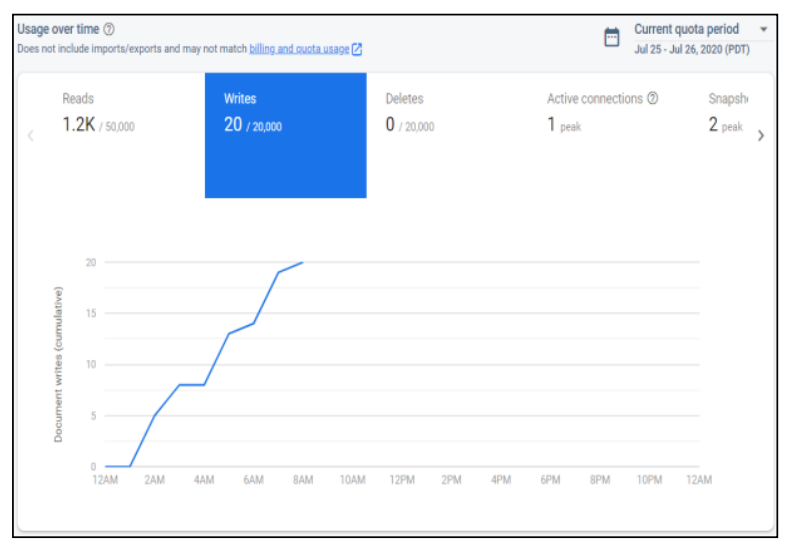

Gambar 19. Performa Firebase

Gambar 19 dapat disimpulkan penggunaan firebase dalam aplikasi E-Tilang ini memiliki performa yang baik dengan ditunjukannya grafik yang meningkat seiring bertambahnya data.

\subsection{Pengujian Sisten}

Pengujian sistem memiliki tujuan untuk memastikan bahwa sebuah sistem yang telah dikembangkan sudah berjalan sesuai dengan fungsionalitas. Pengembang sistem melakukan sesi khusus untuk menguji sistem agar error dapat dideteksi sejak awal. Jenis pengujian yaitu secara black box testing. Black box testing merupakan pengujian kualitas sistem yang berfokus pada fungsionalitas sistem. Pengujian black box testing bertujuan untuk menemukan fungsi yang error, kesalahan tampilan, kesalahan pada struktur data dan kesalahan perfomansi. Pengujian Sistem yang dilakukan pada sistem ini adalah black box testing dengan uraian seperti Tabel 1.

Tabel 1. Tabel Pengujian Sistem

\begin{tabular}{|c|c|c|c|}
\hline Fitur & Harapan & Pengamatan & Hasil \\
\hline $\begin{array}{l}\text { Menu } \\
\text { Login }\end{array}$ & $\begin{array}{l}\text { 1. Dapat } \\
\text { menambahkan } \\
\text { user baru } \\
\text { 2. Dapat } \\
\text { melakukan } \\
\text { verifikasi via } \\
\text { Email pada User } \\
\text { baru } \\
\text { 3. Dapat } \\
\text { mengakses User } \\
\text { yang sudah } \\
\text { terdaftar }\end{array}$ & $\begin{array}{l}\text { 1. Data user } \\
\text { baru berhasil } \\
\text { disimpan \& } \\
\text { dapat } \\
\text { melakukan } \\
\text { verifikasi via } \\
\text { Email } \\
\text { 2. User lama } \\
\text { dapat login }\end{array}$ & Diterima \\
\hline $\begin{array}{l}\text { Menu } \\
\text { Eksekusi } \\
\text { Tilang }\end{array}$ & $\begin{array}{l}\text { 1. Dapat } \\
\text { memasukan data } \\
\text { pelanggar \& } \\
\text { upload gambar } \\
\text { 2. Dapat } \\
\text { mengirimkan } \\
\text { Notifikasi kepada } \\
\text { pelanggar via } \\
\text { SMS }\end{array}$ & $\begin{array}{l}\text { Data berhasil } \\
\text { disimpan } \\
\text { pada } \\
\text { database \& } \\
\text { dapat } \\
\text { mengirimkan } \\
\text { notifikasi } \\
\text { pelanggar } \\
\text { mendapatkan } \\
\text { notifikasi } \\
\text { SMS }\end{array}$ & Diterima \\
\hline $\begin{array}{l}\text { Menu } \\
\text { Profil }\end{array}$ & $\begin{array}{l}\text { Dapat } \\
\text { menampilkan } \\
\text { informasi } \text { user }\end{array}$ & $\begin{array}{l}\text { Data berhasil } \\
\text { disimpan } \\
\text { pada } \\
\text { database }\end{array}$ & Diterima \\
\hline $\begin{array}{l}\text { Menu } \\
\text { Riwayat } \\
\text { E-tilang }\end{array}$ & $\begin{array}{l}\text { Menampilkan data } \\
\text { pelanggar } \\
\text { dan menampilkan } \\
\text { proses tilang }\end{array}$ & $\begin{array}{l}\text { Dapat } \\
\text { Menampilkan } \\
\text { data } \\
\text { pelanggar dan } \\
\text { menampilkan } \\
\text { proses tilang. }\end{array}$ & Diterima \\
\hline $\begin{array}{l}\text { Menu } \\
\text { Prosedur } \\
\text { E-tilang }\end{array}$ & $\begin{array}{l}\text { Menampilkan } \\
\text { prosedur - } \\
\text { prosedur E-tilang }\end{array}$ & $\begin{array}{l}\text { Dapat } \\
\text { menampilkan } \\
\text { procedure- } \\
\text { procedure E- } \\
\text { tilang }\end{array}$ & Diterima \\
\hline
\end{tabular}

\subsection{Pengujian UAT}

User Acceptance Testing adalah tahap akhir pada testing yang dijalankan untuk mengetahui apakah masih terdapat defect pada aplikasi atau software yang dikembangkan. Tahapan pengujian menggunakan angket Skala Likert yang umumnya digunakan untuk dalam riset berupa survei dan memberikan pertanyaan kepada responden (user) dimana jawaban dari pertanyaan tersebut terdiri dari tingkatan yang dapat dipilih seperti Tabel 2.

Tabel 2. Tabel Bobot Nilai Jawaban

\begin{tabular}{clc}
\hline Jawaban & \multicolumn{1}{c}{ Keterangan } & Bobot \\
\hline A & Sangat Setuju & 5 \\
B & Setuju & 4 \\
C & Cukup & 3 \\
D & Kurang Setuju & 2 \\
E & Sangat Tidak Setuju & 1 \\
\hline
\end{tabular}


Berikut ini merupakan pertanyaan yang digunakan 1. Nilai tertinggi $=20 \times 6 \times 5=600$ (seandainya semua peneliti untuk mendapat data pendukung dan butir pertanyaannya. Perhatikan Tabel 3.

Tabel 3. Tabel Daftar Pertanyaan

\begin{tabular}{|c|c|c|}
\hline No & Kode & Pertanyaan \\
\hline 1 & $\mathrm{P} 1$ & Apakah tampilan E-tilang Menarik? \\
\hline 2 & $\mathrm{P} 2$ & $\begin{array}{l}\text { Apakah tampilan menu-menu pada E- } \\
\text { Tilang sesuai dengan konten? }\end{array}$ \\
\hline 3 & P3 & $\begin{array}{l}\text { Apakah E-Tilang dapat membantu } \\
\text { pekerjaan user? }\end{array}$ \\
\hline 4 & P4 & Apakah Konten E-tilang sudah sesuai ? \\
\hline 5 & P5 & Apakah E-tilang mudah dipahami ? \\
\hline 6 & P6 & Apakah E-tilang sudah cukup baik? \\
\hline
\end{tabular}

Tabel 4. Tabel Profil Responden

\begin{tabular}{|c|c|c|c|c|}
\hline No & Parameter & Indikator & Jumlah & Presentase \\
\hline \multirow{2}{*}{1} & Usia & $<25$ Tahun & 20 & $100 \%$ \\
\hline & \multicolumn{2}{|c|}{ Jumlah Responden } & 20 & $100 \%$ \\
\hline \multirow{3}{*}{2} & \multirow{2}{*}{ Jenis Kelamin } & Laki-Laki & 12 & $60 \%$ \\
\hline & & Perempuan & 8 & $40 \%$ \\
\hline & \multicolumn{2}{|c|}{ Jumlah Responden } & 20 & $100 \%$ \\
\hline \multirow{3}{*}{3} & \multirow{3}{*}{ Jenis Pekerjaan } & Mahasiswa & & \\
\hline & & $\begin{array}{c}\text { Jurusan } \\
\text { Teknik }\end{array}$ & 20 & $100 \%$ \\
\hline & & Informatika & & \\
\hline
\end{tabular}

Tabel 4 merupakan tabel profil responden pengujian aplikasi E-tilang. Pengujian UAT dilakukan pada 20 responden dengan latar belakang yang berbeda-beda. Peneliti membagi setiap parameter menjadi 2-4 kategori yang relevan dengan pengujian UAT aplikasi E-tilang ini.

Tabel 5. Tabel Hasil Kuisioner

\begin{tabular}{cccccccc}
\hline \multirow{2}{*}{ No } & Parameter & Pertanyaan & \multicolumn{5}{c}{ Frekuensi Jawaban } \\
\cline { 3 - 7 } & & A & B & C & D & E \\
\hline 1 & Desain & P1 & 9 & 8 & 3 & 0 & 0 \\
2 & Tampilan & P2 & 7 & 7 & 4 & 2 & 0 \\
3 & Konten & P3 & 8 & 6 & 4 & 2 & 0 \\
4 & P4 & 10 & 4 & 4 & 2 & 0 \\
5 & Kemudahan & P5 & 4 & 10 & 6 & 0 & 0 \\
6 & \& Efisiensi & P6 & 7 & 6 & 5 & 2 & 0 \\
& & Total Skor & 45 & 41 & 26 & 8 & 0 \\
\hline
\end{tabular}

Tabel 5 merupakan hasil dari kuisioner, dari data jawaban kuisioner yang diperoleh tersebut kemudian dianalisis dengan menghitung rata-rata skor yang diperoleh dari setiap jawaban responden. Berdasarkan skor yang telah ditetapkan dapat dihitung sebagaimana diperlihatkan di Tabel 6.

Tabel 6. Tabel Jumlah Skor

\begin{tabular}{ccc}
\hline Jumlah Skor & Perkalian & Hasil \\
\hline Jumlah Skor A & 45 X 5 & 225 \\
Jumlah Skor B & 41 X 4 & 164 \\
Jumlah Skor C & 26 X 3 & 78 \\
Jumlah Skor D & $8 \times 2$ & 16 \\
Jumlah Skor E & 0 X 1 & 0 \\
& Jumlah Skor & 483 \\
\hline
\end{tabular}

Hasil jawaban dari responden sebanyak 20 orang tersebut di atas kemudian dapat dihitung nilai tertinggi dan terendah seperti berikut: menjawab A).

2. Nilai terendah $=20 \times 6 \times 1=120$ (seandainya semua menjawab E).

Berdasarkan perhitungan yang menyatakan nilai tertinggi adalah 600 dapat dicari persentase seperti rumus 1 .

$\frac{x}{y} \times 100 \%$

Dengan $x$ adalah jumlah skor, $y$ adalah nilai tertinggi. Dapat diketahui bahwa tanggapan dari responden terhadap sistem aplikasi E-Tilang berdasarkan tingkat penerimaannya adalah kuat, yaitu dengan persentase $80,5 \%$.

\section{Kesimpulan}

Berdasarkan uraian pembahasan penelitian yang telah dibahas maka dapat disimpulkan bahwa aplikasi ini mampu mengurangi penggunaan kertas atau sumber daya lainnya dan juga meminimalisir penyimpangan tindak pidana melanggar lalu lintas. E-tilang mengadaptasi form tilang manual dengan atribut tambahan yaitu nomer handphone pelanggar yang akan dikirimkan melalui sistem E-tilang. Sistem E-tilang menggunakan Firebase Realtime Database, database realtime ini sangat relevan digunakan karena kebutuhan input data saat proses penilangan harus dilakukan secara tepat dan cepat.. Hasil pengujian terhadap Aplikasi Etilang menggunakan UAT menunjukkan 80,5\% responden menerima Penerapan Firebase Realtime Database pada Aplikasi E-Tilang Smartphone berbasis Mobile Android.

\section{Daftar Rujukan}

[1] Q. A. Subavhe Sandy, Hardhienata Soewarto, "Aplikasi ETilang Kendaraan Bermotor Berbasis Android,” 2016.

[2] S. NARTI, "Pemanfaatan 'Whatsapp' Sebagai Media Komunikasi Dosen Dengan Mahasiswa Bimbingan Skripsi (Studi Analisis Deskriptif Pada Mahasiswa Ilmu Komunikasi Bimbingan Skripsi Universitas Dehasen Bengkulu Tahun 2016 )," J. Chem. Inf. Model., vol. 53, no. 9, pp. 1689-1699, 2019, doi: 10.1017/CBO9781107415324.004.

[3] R. Rusdi, A. Wibowo, and Y. D. L. W, "Aplikasi Surat Tilang Berbasis Android Menggunakan Teknologi Near Field Communication ( NFC )," Semin. Nas. Teknol. Inf. Komun. Terap. 2013 (Semantik 2013), vol. 2013, no. November, pp. 305$312,2013$.

[4] A. Veronika, "Implementasi Pelayanan Publik dalam Pengurusan Electronic Tilang ( E-Tilang ) di Satuan Polisi Lalu Lintas ( Satlantas ) Kepolisian Resor Kota Besar Medan," 2018.

[5] G. R. Payara and R. Tanone, "Penerapan Firebase Realtime Database Pada Prototype Aplikasi Pemesanan Makanan Berbasis Android," J. Tek. Inform. dan Sist. Inf., vol. 4, no. 3, pp. 397406, 2018, doi: 10.28932/jutisi.v4i3.870.

[6] ibnu peristiawan Azis, Aplikasi E-Tilang Pada Tablet Sistem Operasi Berbasis Android. 2012.

[7] Y. M. Irsan, "Perspektif Penerapan E-Tilang Dengan Menggunakan Rekaman Cctv (Closed Circuit Television)," Perspekt. Penerapan E-Tilang Dengan Menggunakan Rekam. Cctv(Clossed Circuit Telev. (Studi Kasus Di Wil. Bandar 
Lampung), vol. 15, no. 3, p. 210, 2018, doi: 10.22201/fq. $18708404 \mathrm{e} .2004 .3 .66178$.

[8] I. K. G. Sudiartha, I. N. E. Indrayana, and I. W. Suasnawa, "Membangun Struktur Realtime Database Firebase Untuk Aplikasi Monitoring Pergerakan Group Wisatawan," J. Ilmu Komput., vol. 11, no. 2, p. 96, 2018, doi: 10.24843/jik.2018.v11.i02.p04.

[9] E. A. W. Sanad, "Pemanfaatan Realtime Database di Platform
Firebase Pada Aplikasi E-Tourism Kabupaten Nabire," $J$. Penelit. Enj., vol. 22, no. 1, pp. 20-26, 2019, doi: 10.25042/jpe.052018.04.

[10] W. E. Perry, Effective Methods for Software Testing: Includes Complete Guidelines, Checklists, and Templates. 2007.

[11] W. E. Lewis, Software testing and continuous quality improvement: Third edition. 2016. 